\title{
A Review on Synthesis of Silver NPS from Natural Source and their Applications
}

\author{
Jigisha Modi* and Srushti Patel \\ Shroff S R Rotary Institute of Chemical Technology, India \\ *Corresponding author: Jigisha Modi, Shroff S R Rotary Institute of Chemical Technology, India
}

Submission: 眥 November 01, 2018; Published: 眥 November 26, 2018

\begin{abstract}
Silver Nanoparticles have gained an increasing attention especially in the field of bio medicinal applications, sensor and catalysis. Many techniques are available for synthesis of silver Nanoparticles like chemical reduction, ion sputtering etc., but many of the Nanoparticles synthesis methods involve use of hazardous chemicals or high energy requirements. Hence the popularity of 'Green' environment friendly synthesis of silver Nanoparticles is increasing. Greener synthesis of Nanoparticles also provides advancement over other methods as they are simple, one-step, cost-effective, environment friendly and relatively reproducible and often results in more stable materials. Thus, in the present review we critically assess the role of plants in synthesis of silver Nanoparticles.
\end{abstract}

Keywords: Silver nanoparticles; Green synthesis; Cost-effective

\section{Introduction}

Materials in the nano dimensions (1-100nm) have remarkable difference in the properties compared to the same material in the bulk. With advancement in nanotechnology, a large number of Nanomaterials are appearing with unique properties, opening spectrum of applications and research opportunities. The use of silver as an antibacterial agent is not new, but the application of silver as silver nanoparticles (AgNPs) against various microbes is new. The main reason is their high reactivity due to the large surface to volume ratio. Various methods have been used for the biosynthesis of inorganic material, especially metal Nanoparticles using microorganisms and plants. Silver Nanoparticles have many important applications.

AgNPs have been synthesized by physio-chemical techniques such as chemical reduction, gamma ray radiation, micro emulsion, electrochemical method, laser ablation, autoclave, microwave and photochemical reduction. These methods have effective yield, but they are associated with the limitations like use of toxic chemicals and high operational cost and energy needs. Considering the drawbacks of physio-chemical methods, cost-effective and energy efficient new alternative for AgNPs synthesis using microorganisms, plant extracts and natural polymers as reducing and capping agents are emerging very fast.

In comparison to microorganisms, the application of plant extracts for the synthesis of AgNPs is more advantageous in terms of resource availability, security, reaction rate and convenience, and feasibility of large-scale synthesis [1,2]. It has been proved that many plant extracts are suitable for the phyto-synthesis of
AgNPs [3]. Several factors including $\mathrm{pH}$, dosage of plant extract, dosage of silver ions, reaction temperature and time affect the phyto-synthesis of AgNPs [4,5]. The reduction rate of silver ions is associated with the species of plants and the key active components of plant extracts.

It was studied the green synthesis of silver nanoparticles (AgNPs) from the reduction of a silver nitrate solution (1 and $10 \mathrm{mM}$ ) in the presence of an extract of basil leaves. The synthesized nanoparticles were characterized by UV visible spectroscopy (UVvis), evidencing absorbance at wavelengths of $417 \mathrm{~nm}$ (AgNPs-1) and 414nm (AgNPs10), which are characteristic peaks of this metallic nanoparticles. Scanning Electron Microscopy (SEM) was used to determine the size of the synthesized nanoparticles $[6,7]$.

\section{Conclusion}

This review proved that the phytochemicals components present in the basil leaves/natural source extract can promote the formation of silver nanoparticles at room temperature with a uniform size distribution. This methodology is characterized by its easy performance and its low cost, which contributes to the environmental wealth that is achieved when no toxic compounds are used during the synthesis stage. Finally, the biosynthesised AgNPs were characterised by UV-visible absorption spectroscopy, SEM and TEM.

\section{References}

1. Mittal J, Batra A, Singh A, Sharma MM (2014) Phytofabrication of nanoparticles through plant as nanofactories. Adv Nat Sci Nanosci Nanotechnol 5(4): 043002. 
2. Gavade SJ, Nikam GH, Dhabbe RS, Sabale SR, Tamhankar BV, et al. (2015) Green synthesis of silver nanoparticles by using carambola fruit extract and their antibacterial activity. Adv Nat Sci Nanosci Nanotechnol 6: 045015 .

3. Selvi BCG, Madhavan J, Santhanam A (2016) Preparation of gold nanoparticles by microwave heating and application of spectroscopy to study conjugate of gold nanoparticles with antibody E. coli 0157:H7 Adv Nat Sci Nanosci Nanotechnol 7(3): 035015.

4. Kumar VN, Uchida T, Mizuki T, Nakajima Y, Katsube Y, et al. (2016) Synthesis of nanoparticles composed of silver and silver chloride for a plasmonic photocatalyst using an extract from a weed Solidago altissima (goldenrod). Adv Nat Sci Nanosci Nanotechnol 7(1): 015002.
5. Sathiya CK, Akilandeswari S (2014) Fabrication and characterization of silver nanoparticles using Delonix elata leaf broth. Spectrochim Acta A 128: $337-341$

6. Bernett DM, Granados AS, Torres SN, Herrera A (2016) Chromatographic analysis of phytochemicals components present in mangifera indica leaves for the synthesis of silver nanoparticles by $\mathrm{AgNO}_{3}$ reduction. J Phys Conf Ser 687(1): 012033.

7. Ahmed S, Ahmad M, Babu L, Saiqa I (2015) Journal of Advanced Research 1: 1 .
Creative Commons Attribution 4.0

International License

For possible submissions Click Here

\section{Submit Article}

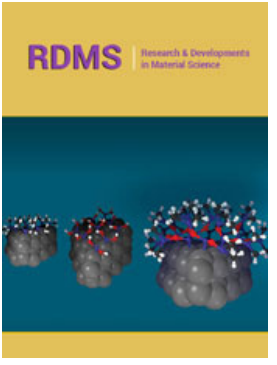

Research \& Development in Material Science

\section{Benefits of Publishing with us}

- High-level peer review and editorial services

- Freely accessible online immediately upon publication

- Authors retain the copyright to their work

- Licensing it under a Creative Commons license

- Visibility through different online platforms 